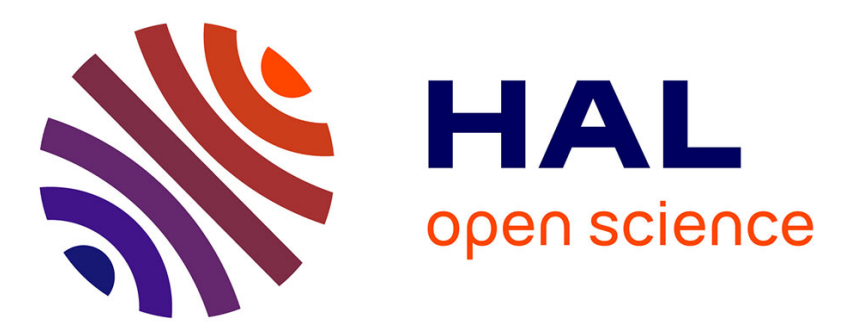

\title{
Oxygen Effect on the Stability of PECVD Boron-Carbon Films
}

\author{
S. Rybakov, V. Sharapov, L. Gavrilov
}

\section{To cite this version:}

S. Rybakov, V. Sharapov, L. Gavrilov. Oxygen Effect on the Stability of PECVD Boron-Carbon Films. Journal de Physique IV Proceedings, 1995, 05 (C5), pp.C5-921-C5-926. 10.1051/jphyscol:19955109 . jpa-00253777

\section{HAL Id: jpa-00253777 https://hal.science/jpa-00253777}

Submitted on 1 Jan 1995

HAL is a multi-disciplinary open access archive for the deposit and dissemination of scientific research documents, whether they are published or not. The documents may come from teaching and research institutions in France or abroad, or from public or private research centers.
L'archive ouverte pluridisciplinaire HAL, est destinée au dépôt et à la diffusion de documents scientifiques de niveau recherche, publiés ou non, émanant des établissements d'enseignement et de recherche français ou étrangers, des laboratoires publics ou privés. 


\title{
Oxygen Effect on the Stability of PECVD Boron-Carbon Films
}

\author{
S.Yu. Rybakov, V.M. Sharapov and L.E. Gavrilov \\ Institute of Physical Chemistry, Academy of Sciences, Leninsky prosp. 31, Moscow 117915, Russia
}

\begin{abstract}
Stability of thin boron-carbon films on silicon substrates was studied. EPMA measurements were used for the film characterization. If the background pressure in the setup was lower than $5 \times 10^{-6}$ Torr the oxygen content in the films did not exceed 3 at.\%. The concentration of oxygen in the films increased considerably as a result of bad basic vacuum or insufficient degassing of precursor. While exposed in air for several months the films gradually increased their oxygen content up to 20 at.\%. Futher measurements demonstrated no changes in the film composition. The films in which initial oxygen concentration was more than 50 at.\% proved to be unstable and tended to disappear at room temperature within a month. Carbon and boron X-ray emission spectra measured by EPMA technique were used to study the chemical bonds in these films. It was shown that the chemical bonds have been formed between boron and oxygen atoms if oxygen concentration exceeded 36 at.\%. This phenomenon was not observed for the films with low initial oxygen concentration. The ways of the film evaporation are discussed.
\end{abstract}

\section{INTRODUCTION}

At present amorphous boron-carbon films are used as a protective coating for inner surface of the fusion devices. Application of the coatings reduces plasma impurities and improves plasma parameters in tokamaks due to preventing $\mathrm{D}$-ions and metal surface interaction. Carborane which is a harmless crystalline powder with high value of saturated vapor pressure was used as a precursor. The films were first obtained in a glow discharge laboratory setup and then PECVD technique was used in $\mathrm{T}-3 \mathrm{M}$ and T-11M Russian tokamaks [1,2]. A number of analytical methods (EPMA, SIMS, TEM, ellipsometry etc.) were used for the film characterization $[3,4]$. It was shown that $\mathrm{B} / \mathrm{C}$ ratio grew from 1.0 to 3.6 under the increasing carborane pressure and it did not depend on the other factors, such as substrate temperature and voltage applied. The hydrogen content measured by SIMS, RBS and ERD technique was approximately 30 at.\% of the sum of boron and carbon concentrations. The coatings proved to be uniform along the surface and in depth. The deposition rate was about 150 $\mathrm{nm} / \mathrm{h}$ and the film thickness was usually in the range from 50 to $600 \mathrm{~nm}$. The film density calculated on the basis of linear and mass thickness was equal to $1.6 \mathrm{~g} / \mathrm{cm}^{3}$. It should be mentioned that the boron-carbon coatings had high erosion resistance to the ion and plasma irradiation [5]. For example, the film erosion yield under deuterium plasma irradiation was ten times lower than the graphite one. Unfortunately, films with high oxygen concentration were found to be unstable and volatilized at room temperature. The inital oxygen content in the coatings depended strongly on the purity of the precursor and on the vacuum conditions. In addition, the films absorbed oxygen (or water vapor) from air and from residual gases during ion irradiation. The main purpose of the paper is to study oxygen influence on the boron-carbon film stability. 


\section{EXPERIMENTAL PROCEDURES}

The boron-carbon films were deposited on the single crystall silicon substrates in the $\mathrm{dc}$ glow discharge setup. The scheme of the setup was described in detail in [2]. Carborane $\mathrm{C}_{2} \mathrm{~B}_{10} \mathrm{H}_{12}$ was used as a precursor. Unlike diborane and trymethylborane used previously, this substance is accident proof and is non-toxic. The deposition was carried out at substrate temperature $420 \mathrm{~K}$ and carborane vapor pressure $10^{-2}$ Torr. The ion energy was $20 \mathrm{eV}$, the ion flux was about $10^{16} \mathrm{~cm}^{-2} \mathrm{~s}^{-1}$.

Electron probe microanalysis (EPMA) proved to be the most suitable method for measurement of the boron-carbon film composition [3,6]. Although it was originally designed to study bulk samples the recent computational achievements provide quantitative analysis of thin films as well. EPMA is more reliable method than AES and XPS because the signal is formed not only by a shallow layer close to the surface but by the film as a whole. Special EPMA technique was developed for the boron-carbon film characterization [3]. Measurements were carried out using microanalyser CAMEBAX equipped with conventional lead stearate crystal for light element analysis. Accelerating voltage was $10 \mathrm{kV}$ and beam current was $100 \mathrm{~mA}$ at the normal beam incident and 40 take off angle. Boron, diamond and silicon dioxide were used as standards for boron, carbon and oxygen elemental analysis correspondingly. The analysis of the targets comprising light elements is complicated by the chemical shifts which affect the shape and position of X-ray emission lines. As for the shape, the area-peak correction procedure described in [7] was applied. The area-peak factors for boron, carbon and oxygen were measured carefully in special experiments. The shift of line positions was taken into account due to additional spectrometer adjustment prior the measurements.

Elemental composition (except for hydrogen) and mass thickness of the coatings were calculated using a coninuter code based on Yakovitz-Newbury method [8]. The algorithm took properly into account $\mathrm{X}$-ray absorption inside a film (mass absorption coefficients were taken from $[7,9,10]$ ), that is of special importance for the light element analysis. Secondary fluorescence was not taken into account because it is negligibly small in B-C-O systems. It should be noted that although there is up to 30 at.\% of hydrogen in the film, it does not affect boron, carbon and oxygen radiation intensities [6] and may be neglected. The accuracy of the analysis is derived from the statistical uncertainty in $X$-ray intensity measurements $(3-5 \%)$ and the calculation error $(\sim 7 \%)$. The accuracy of mass thickness and composition determinations was about $10 \%$, the accuracy of $\mathrm{B} / \mathrm{C}$ ratio calculation was better than $15 \%$.

A number of boron-carbon films were deposited on silicon substrates under various vacuum conditions. Out of these the six samples with the oxygen content from 2 to 76 at. $\%$ (see table 1) were selected for the futher investigation.

Table 1: Thickness and composition of boron-carbon films with various oxygen content

\begin{tabular}{|l|c|c|c|c|c|c|}
\hline Sample number & $\# 1$ & $\# 2$ & $\# 3$ & $\# 4$ & $\# 5$ & $\# 6$ \\
\hline Boron, at.\% & 73 & 65 & 63 & 65 & 47 & 16 \\
\hline Carb on, at.\% & 25 & 24 & 22 & 19 & 17 & 8 \\
\hline Oxygen, at.\% & 2 & 11 & 15 & 16 & 36 & 76 \\
\hline B/C ratio & 2.9 & 2.8 & 2.9 & 3.5 & 2.7 & 2.0 \\
\hline Thickness, nm & 550 & 500 & 430 & 360 & 90 & 400 \\
\hline
\end{tabular}




\section{RESULTS AND DISCUSSION}

It was shown that the oxygen content in the films did not exceed 3 at. \% if the residual gas pressure in the setup was lower than $5 \times 10^{-6}$ Torr. The concentration of oxygen in the films increased as a result of bad basic vacuum or insufficient degassing of precursor. The films with initial oxygen content more than 50 at.\% were unstable and volatiled at room temperature when stored in air. As indicated in fig. 1 the mass thicknesses of boron and oxygen decreased gradually within a month. On the contrary the mass thickness of carbon increased due to absorption of carbon-containing molecules from air, but it returned to its initial value after annealing at $870 \mathrm{~K}$. Futher measurements showed no changes in the film composition. All boron atoms which remained in the film must have formed the stable boron-carbon bonds. The atomic composition of volatile part of the film was calculated on the basis of the mass thickness variations and it was shown to follow approximately to $\mathrm{BO}_{3}$ formula (except for hydrogen).

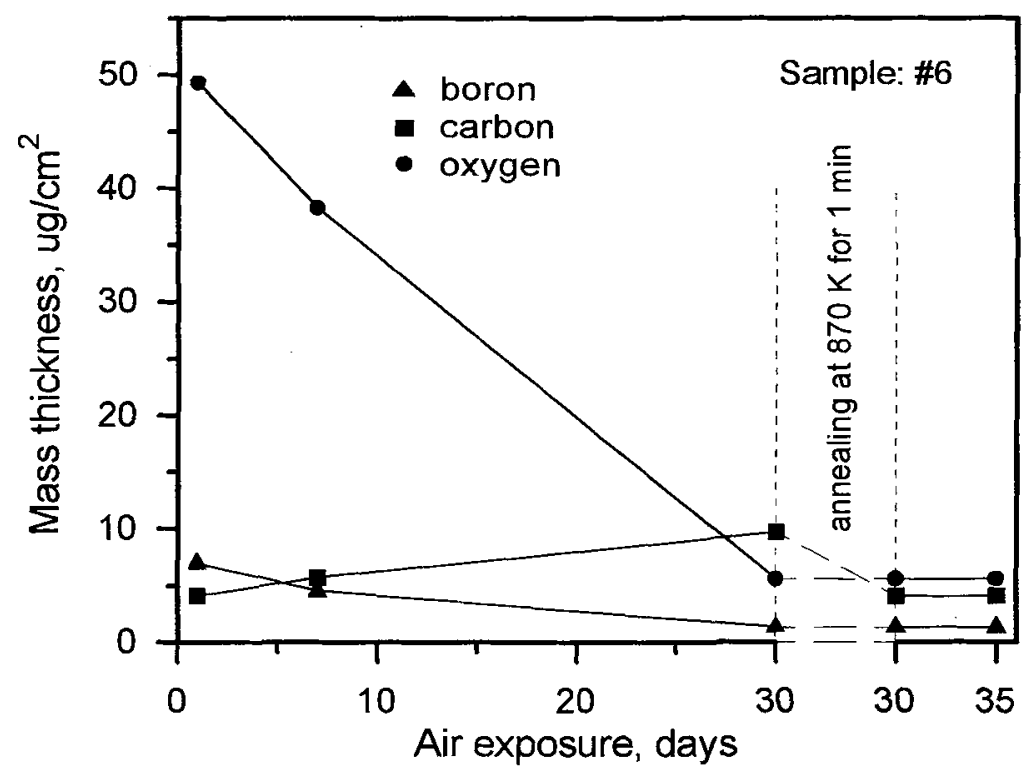

Figure 1: Mass thickness decrease for the film with high oxygen content during exposure in air at room temperature.

As mentioned above the chemical effects on X-ray lines may cause errors in quantitative elemental analysis. On the other side this phenomenon can be used to obtain information on chemical bonding. Boron and carbon $\mathrm{K}_{\alpha}$ emission spectra obtained by EPMA technique are shown in fig.2 and fig.3. The carbon spectra were exactly the same for all the samples i.e. oxygen did not affect shape and position of carbon emission line. In contrast, boron X-ray spectra were changed significantly for the films with high oxygen content (curves 2 and 3 in fig.3). Moreover these spectra can be fitted by the equations:

$$
\begin{aligned}
& F_{2}(\lambda)=0.75 F_{1}(\lambda)+0.25 F_{4}(\lambda), \\
& F_{3}(\lambda)=0.60 F_{1}(\lambda)+0.40 F_{4}(\lambda),
\end{aligned}
$$

where $F_{\hat{i}}(\lambda)$ - the experimental boron $X$-ray spectra indicated in fig.3. 


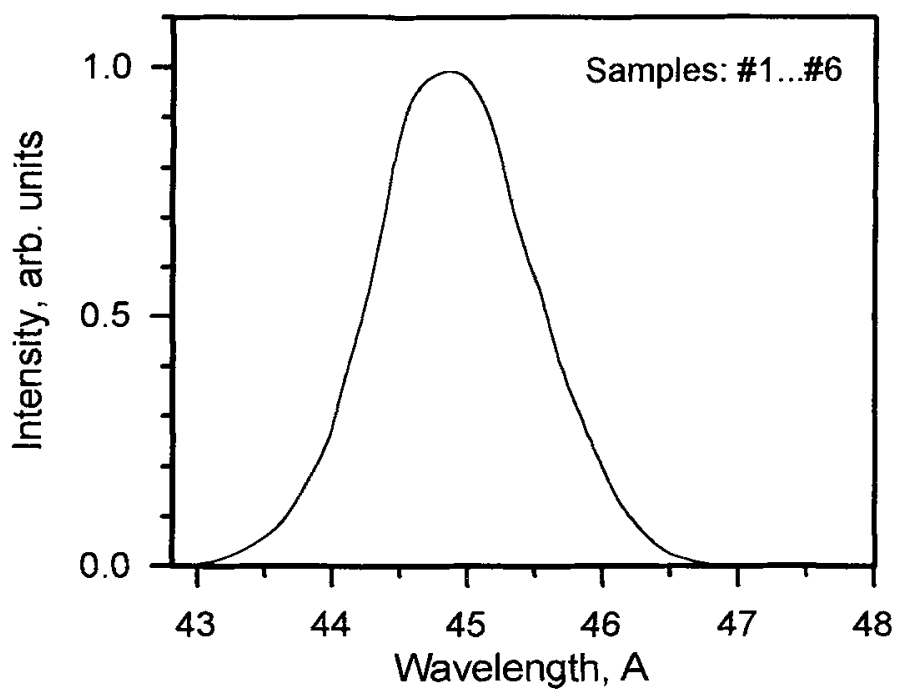

Figure 2: Carbon $\mathrm{K}_{\alpha}$ spectrum for the films with various oxygen concentration.

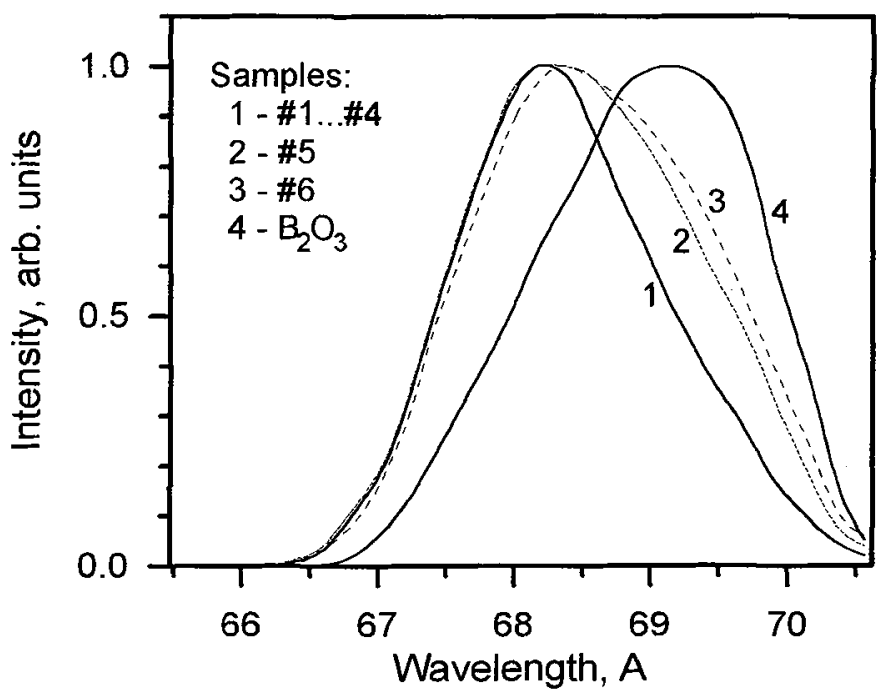

Figure 3: Boron $K_{\alpha}$ spectra for the films with low (1) and high $(2,3)$ oxygen concentration and for boron oxide (4). 
The data obtained show that oxygen accumulation in the films during the deposition resulted in formation of the boron-oxygen chemical bonding and the type of the bond is similar to boron oxide one. It should be emphasize that the formation of boron oxide occured during the film deposition only. As it was demonstrated earlier the boron-carbon films absorbed oxygen or water vapor from air but the concentration of oxygen never exceeded the saturation value $(20$ at.\%) and the films never became volatile [3].

Oxidation of boron-carbon materials was described in a number of papers and it was shown that the interaction of water vapor and oxygen with boron-doped graphites occurs by two consecutive stages [11-13]. The first stage of the oxidation results in boron oxide formation and the second one is associated with the following reactions:

$$
\begin{aligned}
\mathrm{B}_{2} \mathrm{O}_{3}+\mathrm{H}_{2} \mathrm{O} & \rightarrow 2 \mathrm{HBO}_{2}, \\
\mathrm{HBO}_{2}+\mathrm{H}_{2} \mathrm{O} & \rightarrow \mathrm{H}_{3} \mathrm{BO}_{3} .
\end{aligned}
$$

We suggest that the similar processes took place under the film oxidation. In our case boron oxide was formed during the film deposition. According to Litz [12] water vapor can react with boronated graphite at temperatures as low as $523 \mathrm{~K}$ and the reaction with dry air is detectable at temperatures of the order of $723 \mathrm{~K}$. In our experiments the deposition temperature was $420 \mathrm{~K}$ but the reaction of boron oxidation may be enhanced by plasma irradiation. $\mathrm{B}_{2} \mathrm{O}_{3}$ formation due to boron and boron carbide irradiation by low energy $\mathrm{O}^{+}$ions was observed by Zehringer et al. [14]. It seems most probable that the next stage of the film oxidation (i.e. boron oxide and water interaction according to reactions (3) and (4)) occured after the deposition. The boron-carbon films proved to absorb water vapor from air so $\mathrm{H}_{2} \mathrm{O}$ can react slowly with boron oxide forming volatile molecules of boric acid. The film evaporation in the form of boric acid molecules is supported by the $\mathrm{BO}_{3}$ formula for the volatile part of the films. These conclusions are in agreement with the results obtained by Alimov et al. [13] on boron-doped graphites.

\section{CONCLUSION}

The boron-carbon films in which initial oxygen content exceeded 50 at.\% proved to be unstable and tended to volatilize within a month. The film evaporation was found to be connected with boron oxidation. The films with low initial oxygen concentration absorbed oxygen from air during several months but they did not ever become volatile. All the films with initial oxygen concentration lower than 15 at.\% can be used for the tokamak application.

\section{Acknowledgments}

The authors would like to thank Dr.V.Kh.Alimov for helpful discussions. One of the authors (S.Yu.Rybakov) is also grateful to the International Science Foundation for the individual grant.

\section{References}

[1] Buzhinsky O.I. et al., J. Nucl. Mat. 191-194 (1992) 1413-1416.

[2] Sharapov V.M. et al., J. Nucl. Mat. 191-194 (1992) 508-511.

[3] Kanaev A.I., Rybakov S.Yu. and Churaeva M.N., J. Phys. IV France 3 (1993) C3-183-188.

[4] Alimov V.Kh. et al., J. Nucl. Mat. 196-198 (1992) 670-675.

[5] Sharapov V.M. et al., "Erosion of $\alpha-\mathrm{B} / \mathrm{C}: \mathrm{H}$ films under deuterium plasma irradiation", $J$. Nucl.

Mat. (1995) - in press. 
[6] Karduck P. et al., Fresenius J. Anal. Chem. 341 (1991) 315-319.

[7] Bastin G.F. and Heijligers H.J.M., Quantitative Electron Probe Microanalysis of Boron in Binary Borides (Univ. of Technology, Eindhoven, 1986) p.7.

[8] Goldstein J.I., Scanning Electron Microscopy and X-Ray Microanalysis (Plenum Press, New York and London, 1981) p.94.

[9] Bastin G.F. and Heijligers H.J.M., Quantitative Electron Probe Microanalysis of Oxygen (Univ. of Technology, Eindhoven, 1989) p.10.

[10] Bastin G.F. and Heijligers H.J.M., Quantitative Electron Probe Microanalysis of Carbon in Binary Carbides (Univ. of Technology, Eindhoven, 1990) p.6.

[11] Woodley R.E., Carbon 7 (1969) 609-613.

[12] Litz L.M. and Mercuri R.A., J. Electrochem. Soc. 110 (1963) 921-925.

[13] Alimov V.Kh., Zalavutdinov R.Kh. and Sherzer B.M.U., J. Nucl. Mat. 212-215 (1994) 14611466.

[14] Zehringer R. et al., J. Nucl. Mat. 176-177 (1990) 370-374. 